\title{
EDITORIAL
}

\section{Nature's bounty of natural products brings bewildering outcomes}

Earth is home to about 250,000 different species of plants, and to over 30 million species of fungi, algae, and bacteria. Despite these vast numbers, chemists have tested only a few of these organisms to see whether they harbor medically useful small molecules called natural products. In addition, there is increasing evidence that lower plants such as lichens, hitherto not examined, might be a rich repository of bioactive natural products (Karunaratne et al., 2005).

It is a long held truism that natural products and/or natural product structures have continued to play a seminal role in the drug discovery and development process. However, a shift to combinatorial synthesis took over the pharma industry in the early 2000s. Inauspiciously, the projected swell of "natural product like" New Chemical Entities (NCE) did not emerge through combinatorial synthesis. These efforts yielded only one antitumor de novo NCE, sorafenib, approved by the Food and Drug Administration (FDA) in 2005 (Newman and Crag, 2012). Thus, there is an increasingly compelling case for revisiting natural products for drug discovery.

Historically, natural products from plants and animals were a fount of essentially all medicines. A detailed analysis of new medicines approved by the FDA between 1981 and 2010 revealed that $34 \%$ of those medicines that were based on small molecules were natural products or direct derivatives of natural products (Newman and Crag, 2012). Clearly, the new emerging paradigm about natural products is that diversity within biologically relevant 'chemical space' is more important than the compound library size, acquired through other means. Natural product libraries show a wide assortment of pharmacophores and are rich in stereochemistry. Such advantages lead to hits, even against the more difficult screening targets, such as protein- protein interactions (Drewry and Macarron, 2010). Importantly, natural products are "natural metabolites", and by definition must possess metabolite-likeness. For example, in the area of cancer, between the periods from around the 1940s to date, of the 175 small molecules which made the mark, $48.6 \%$ actually being either natural products or directly derived there from.

Natural products have provided the starting points for most of the major classes of antibiotics, including the $\beta$-lactams, aminoglycosides, macrolides, tetracyclines, rifamycins, glycopeptides, streptogramins and lipopeptides. Since 2000, 22 new antibiotics have been launched for treating infections in humans, although only five of these represented new compound classes (Butler et al., 2013). Three of these new classes have their origins in natural products: the lipopeptide daptomycin, fill gaps the pleuromutilin retapamulin and the tiacumicin fidaxomicin. Of the identified 56 antibiotics that were undergoing clinical trials in 2013, nineteen represented new structural templates and eleven were related to natural products (Butler et al., 2013). In the past 30 years, natural-product research has also provided the only new class of antifungal drugs - the echinocandins (Roemer and Krysan, 2014). 
A completely different emergence of natural products is in the area of siderophors. Despite being one of the most abundant elements in the Earth's crust, the bioavailability of iron in many environments such as the soil or sea is limited by the very low solubility of the $\mathrm{Fe}^{3+}$ ion. This is the predominant state of iron in aqueous, non-acidic, oxygenated environments. It accumulates in common mineral phases such as iron oxides and hydroxides. Small molecules natural products, siderophores, secreted by fungi, bacteria and grasses are amongst the strongest soluble $\mathrm{Fe}^{3+}$ binding agents known (Jayasinghe et al., 2015). Siderophore type compounds such as polyphenols (found in plants and bacteria) and hydroxamic acids (found in bacteria) highlights their importance at the soil/microorganism/plant interphases (Karunaratne et al., 1992).

Organic synthesis is the bridge between natural products and their viability of being used as drugs. Natural products themselves played a crucial role in the emergence and advancement of organic synthesis from its birth to the present day. Nature's thermodynamically stable portfolio of five and six-membered ring natural products inspired synthetic organic chemists to embark on over two centuries of active research in natural product synthesis. With tremendous advances in annulation reactions leading to ring synthesis (Piers and Karunaratne, 1983), new reactions and catalysts, synthetic organic chemists have the power to replicate some of the most fascinating molecules of nature's creations in the laboratory and apply the mature synthetic strategies and technologies to construct variations of them. Such molecules facilitate the understanding of biology and medicine, as they often find uses as biological tools and drug candidates for clinical development (Nicolaou, 2014).

Thus, a strong case needs to be made for expanding, not decreasing, the exploration of Nature as a source of novel active agents which may serve as the leads and scaffolds for elaboration into urgently needed efficacious drugs for a multitude of disease indications.

\section{REFERENCES}

Butler, M. S., $\quad$ Blaskovich, M. A., $\quad$ Coper, M. A. (2013). Antibiotics in the clinical pipeline in 2013. Journal of Antibiotics 66: 571-591.

Drewry, D. H., Macarron, R. (2010). Enhancements of screening collections to address areas of unmet medical need: an industry perspective. Current Opinion in Chemical Biology14: 289-298.

Jayasinghe, S., Siriwardhana, A.S., and Karunaratne, V. (2015).Natural iron sequesteringa gents: their roles in nature and therapeutic potential, International Journal of Pharmacy and Pharmaceutical Science 7(9), 8-12.

Karunaratne, V., Hoveyda, H.R., Orvig, C. (1992). General method for the synthesis of trishydroxamicacids, Tetrahedron Letters 33: 1827-1830.

Karunaratne, V., Bombuwela, K., Kathirgamanathar, S., Thadhani, V.M. (2005). Lichens: a chemically important biota, Journal of National Science Foundation 33: 169-86.

Newman, D. J., Cragg, G. M. (2012). Natural products as sources of new drugs over the 30 years from 1981 to 2010. Journal of Natural Products75: 311-335.

Nicolaou K. C. (2014) Organic synthesis: the art and science of replicating the molecules of living nature and creating others like them in the laboratory. Proceedings of the Royal Society A 470: 20130690.

Piers, E., Karunaratne V. (1983). Conjugate addition of lithium phenylthio- and cyano-[2-(4chlorobut-l-enyl) cuprate to cyclic enones. An efficient methylenecylcopentane annulation process. Journal of the Chemical Society Chemical Communications 17: 935-936.

Roemer, T.,Krysan, D. J. (2014). Antifungal drug development: challenges, unmet clinical needs, and new approaches. Cold Spring Harbor Perspectives in Medicine 4: a019703.

Veranja Karunaratne 